\title{
Depiction of Major Mite Allergens in Severe Allergic Rhinitis with High Mite Perennial Exposure
}

\author{
Original Investigation $>$ Ruperto González-Pérez ${ }^{1}$ (D), Paloma Poza-Guedes ${ }^{1}$ (D), Fernando Pineda ${ }^{2}$ (D), Miriam Castillo ${ }^{2}$ (1) \\ ${ }^{1}$ Department of Allergy \& Severe Asthma Unit, Hospital Universitario de Canarias, Tenerife, Spain \\ ${ }^{2}$ Diater Laboratory, Madrid, Spain
}

Abstract

ORCID iDs of the authors:

R.G.P. 0000-0002-6664-0276;

P.P.G. 0000-0001-8516-6648;

F.P. 0000-0003-2173-0013;

M.C. 0000-0003-4515-2377.

Cite this article as: González-Pérez R, PozaGuedes P, Pineda F, Castillo M. Depiction of Major Mite Allergens in Severe Allergic Rhinitis with High Mite Perennial Exposure. Turk Arch Otorhinolaryngol 2020; 58(3): 155-62.

\section{Corresponding Author:}

Ruperto González-Pérez, glezruperto@gmail.com

Received Date: 13.04 .2020

Accepted Date: 25.08.2020

Content of this journal is licensed under a Creative Commons Attribution 4.0 International License. Available online at www.turkarchotolaryngol.net
Objective: Airway diseases, including allergic rhinitis, are prompted by specific $\operatorname{IgE}$ antibodies against airborne allergens and notably those derived from mites. The presented study focused on the specific IgE immediate response to Dermatophagoides pteronyssinus ( $D$. pteronyssinus) mite major allergens and the corresponding pertinence of molecular diagnosis in patients bothered with severe persistent rhinitis.

Methods: Individuals exhibiting confirmed sensitization to $D$. pteronyssinus along with a clinical diagnosis of coexisting severe allergic rhinitis were included in the study. In vivo investigations encompassed intradermal testing with a battery of standardized allergenic extracts, concurrent with in vitro specific $\mathrm{IgE}$ to the crude extract of $D$. pteronyssinus, and associated individual molecular allergens were assessed.

Results: Fifty-five out of 59 subjects showed sero- dominant $\operatorname{Ig} \mathrm{E}$ responses to the major allergens Der $\mathrm{p}$ 1, Der p 2 and Der p 23. Both Der p 2 and Der p 23 reached a prevalence above $80 \%$, while group 10 allergen tropomyosin was scarcely depicted $(<10 \%)$ and exclusively present in younger individuals.

Conclusion: The proposed component-resolved diagnosis panel accurately recognized $93.22 \%$ of $D$. pteronyssinus allergic patients. The raised seroprevalence of $\operatorname{IgE}$ response to Der p 23 also confirmed this constituent as a major $D$. pteronyssinus allergen in severe allergic rhinitis. A molecular approach appears to be essential to frame a more precise diagnosis and eventually a personalized immunotherapy regarding this allergic condition.

Keywords: Allergen, allergic rhinitis, Dermatophagoides pteronyssinus, component-resolved diagnosis, house dust mite

\section{Introduction}

Airborne allergens sensitize and favor the development of allergic rhinitis, asthma, and atopic disease in genetically predisposed individuals (1, 2). The European house dust mite (HDM) Dermatophagoides pteronyssinus (D. pteronyssinus) is of significant clinical importance as a major elicitor of asthma, allergic rhinitis, and atopic dermatitis (3). Mite allergens are present in mite bodies, in secretion and excretion, with fecal pellets of the HDM as the main sources of indoor allergens worldwide. Although mite allergens can be detected in many areas of the home, beds are the perfect habitat for mites since they provide the ideal temperature, food and moisture for their proliferation and the allergens they produce accumulate inside mattresses and pil- lows (4). The prevalence of sensitization to mites rises to $90 \%$, with geographical variations, in the respiratory allergic population $(5,6)$. The dominant causative allergen in a specific community may be locally dissimilar among subjects and the intended underlying atopic disease $(7,8)$.

Purified allergens are given standardized names by a $\mathrm{WHO} /$ International Union of Immunological Societies committee based on the order of their discovery and their sequence homology. To date, 39 Dermatophagoides spp. (Pyroglyphidae) allergens have been documented through specific $\operatorname{IgE}$ ( $\operatorname{sgE}$ ) binding or skin test reactivity (9), with noticeable differences in the distribution (seroprevalence) of the major Der p 1 and Der p 2 allergens across regions $(9,10)$. Two types 
of HDM allergen bioactivity, namely proteolysis-Der $\mathrm{p} 1$, a $24 \mathrm{kDa}$ cysteine protease, with significant consequences for allergic sensitization-and peptidolipid/lipid binding as Der p 2 acting as a ligand to TLR-4, elicit IgE and stimulate immune-responses to unrelated allergens (11). Moreover, group 10 muscle protein tropomyosin, which has been involved in immunological cross-reactions among invertebrates-mainly mollusks and arthropods- have also exhibited varying profiles of $\operatorname{sgE}$ response to Der p 10 (12). Der p 23-a $14 \mathrm{kDa}$ peritrophin from the mite gut is present in the outer membrane of mite feces-has been described as the latest major HDM allergen inducing persistent respiratory symptoms when the aforementioned Der p 1, Der p 2 and Der p 10 are not recognized (13). Although different repertoires of specific HDM allergen sensitization have been investigated in asthma $(14,15)$, the role of molecular diagnosis in persistent allergic rhinitis has received little attention in the literature. Severe allergic rhinitis (SAR) is defined as a highly prevalent condition affecting both children and adults, leading to a deleterious impact on people's daily lives $(16,17)$, and moreover, favoring the further development of asthma (18). The perennial character of SAR is closely linked to the more temperate regions while the bi-annual rhythmicity is frequent in the Mediterranean areas, related to the correspondent HDM lifecycle (19).

Component-resolved diagnosis (CRD) allows the comprehensive assessment of the patient's allergen-specific $\operatorname{IgE}$ (sIgE) binding to a panel of individual allergens $(20,21)$. Although Dermatophagoides spp. group 1, 2 and 23 allergens are immunodominant-referring to allergens that quantitatively make the most important contribution to

\section{Main Points}

- Today, it is recognized that atopic sensitization is an important risk factor in respiratory conditions (i.e., allergic asthma) in both adults and children. However, the role of allergy concerning certain asthma phenotypes—-such as severe asthma—is still under debate.

- Allergic rhinitis is a highly prevalent condition worldwide, affecting children and adults, and in the severe form of the disease leading to noticeable morbidity and impaired life quality, thus serving as a risk factor for the development of asthma.

- Even though different repertoires of specific house dust mite allergen (HDM) sensitization have been described in persistent asthma, there is a lack of studies involving a wide diagnostic panel (or specific IgE repertoire) of HDM allergens in severe allergic rhinitis.

- Geographic variation complicates the picture: although HDM allergy is consistently found in Western nations, diversity (allergen serodominance) between countries and regions is notable.

- Our results propose that a component-resolved diagnosis panel facilitates a more precise Dermatophagoides pteronyssinus molecular diagnosis, especially in severe rhinitic subjects with a-climate conditioned-high-mite allergen exposure, heightening the prevalence of Der p 2 and Der p 23 in this condition. the $\operatorname{IgE}$ responses-the association among major allergens and evolving clinical phenotypes has not been assessed (22, 23). The presented study investigates the $\operatorname{IgE}$ sensitization repertoire to $D$. pteronyssinus and the outcome of CRD in subjects with SAR and a sharp perennial exposure to HDM (24). Herein, a specific customized molecular panel for $D$. pteronyssinus was comprised including Der $\mathrm{p} 1$, Der $\mathrm{p} 2$, the recently described peritrophin-like protein Der p 23 and Der p 10 as a cross-reacting biological marker between HDM and seafood allergy.

\section{Methods}

\section{Subjects}

The presented study was previously evaluated and authorized by the domestic Ethical Committee of the Nuestra Señora de Candelaria University Hospital (Approval Date: March 28, 2017; Approval Number: P.I.-14/17), and corresponding informed consent documents were properly signed by all participants. Inclusion criteria required a signed informed consent, a previous clinical diagnosis of present $\mathrm{SAR}$, and a positive immediate intradermal test (SPT) with $\operatorname{sgE} \geq 0.35$ $\mathrm{kU}_{\mathrm{A}} / \mathrm{L}$ to $D$. pteronyssinus in both cases. Pregnant and breast-feeding women were excluded.

Patients were exclusively recruited from the Allergy Outpatient facility, with a consistent diagnosis of SAR according to the ARIA guidelines (17). Disease severity was evaluated by means of patient self-assessment over a validated scale score of six individual nasal and ocular symptoms (sneezing, rhinorrhea, nasal pruritus, nasal congestion, ocular pruritus and watery eyes) on a scale of 0-3 on the day of the visit. The sum of the six symptom points yielded the rhinoconjunctivitis total symptom score (RTSS) on the day of the visit ranging from 0 to 18 points $(25,26)$.

Blood specimens were collected, identified with code label, stored at $-40^{\circ} \mathrm{C}$ and immediately thawed in preparation for in vitro analysis.

\section{Skin Prick Test and Mite Allergenic Extracts}

Percutaneous tests were performed according to the European standards (27) with standardized allergenic extracts of D. pteronyssinus (Diater, Madrid, Spain). Saline (0.9\%) and histamine $(10 \mathrm{mg} / \mathrm{mL})$ were respectively included as negative and positive controls. Antihistamines were stopped seven days in advance to each SPT, with wheal diameters $>3 \mathrm{~mm}$ considered positive after a 20-minute immediate reading. Concerning allergenic HDM extracts, proteins from mite bodies of $D$. pteronyssinus were extracted into phosphate buffered saline buffer $0.01 \mathrm{M}, \mathrm{pH} 7.4$, for 2 hours at $5 \pm 3^{\circ} \mathrm{C}$. Both protein solutions were clarified by filtration and centrifugation (1 hour at 16,000 g). The obtained supernatants were then ultrafiltrated for purified water, sterile filtered, frozen and finally lyophilized. 


\section{Serological Workup, SDS PAGE \& IgE Western Blot}

Total IgE levels, sIgE to the whole D. pteronyssinus extract, and four individual molecular allergens-Der $\mathrm{p} 1$, Der p 2, Der p 10 and Der p 23-were measured by ImmunoCAP and Immuno Solid-phase Allergen Chip (ISAC) multiplexing (ThermoFisher Scientific, Uppsala, Sweden) following the endorsed manufacturer's guidelines. The total $\mathrm{IgE}$ titers were quantified in international units per unit volume $(\mathrm{kU} / \mathrm{L})$ while $\operatorname{sg} \mathrm{E}$ levels were quoted in $\mathrm{kU}_{\mathrm{A}} / \mathrm{L}$ with a cut-off value $\geq 0.35 \mathrm{kU} / \mathrm{L}$. In relation to sodium dodecylsulfate polyacrylamide gel electrophoresis (SDS-PAGE) and $\operatorname{IgE}$ Western blot (WB) assays, proteins from D. pteronyssinus allergenic extracts were analyzed in $15 \%$ polyacrylamide gels under reducing conditions as elsewhere detailed (28). Proteins were stained by Coomassie Brilliant Blue R-250 and transferred to polyvinylidene difluoride (Transblot turbo Biorad ${ }^{\circledR}$, California, US) while IgE-binding was shown by BioRad Diversity database software. The specific binding of $\operatorname{IgE}$ to allergens was performed by $\mathrm{WB}$, through individual participant's sera against anti-human $\operatorname{IgE}$ peroxidase-conjugate (Southern Biotech, US) and chemiluminescence reagents (Western lightning ${ }^{\circledR}$, Perkin Elmer, Massachusetts, US) were carried out following supplier's indications.

\section{Statistical Analysis}

Demographic features were quoted following standard descriptive means, including the corresponding minimum-maximum ranks, and medians were quoted with standard deviations if continuous variables, or percentages when categorical variables through the IBM Statistical Package for Social Sciences for Windows version 25.0 (IBM SPSS Corp.; Armonk, NY, USA). To quantify deviations in variance, Kruskal-Wallis, or chi-square test were used for parametric continuous, nonparametric continuous, and categorical variables. A p-value of less than 0.05 was considered statistically significant.

Table 1. Descriptive statistics

\begin{tabular}{l|c|c|c}
\hline & Total (n) & $<\mathbf{1 8}$ y.o. & $>\mathbf{1 8}$ y.o. \\
\hline $\mathrm{n}$ & 59 & $22(37.28 \%)$ & $37(62.71 \%)$ \\
\hline Age (y.o.) & $25.8(9-70)$ & $13.7(9-18)$ & $36.4(19-70)$ \\
\hline Sex (F/M) & $35 / 24$ & $(15 / 10)$ & $(20 / 14)$ \\
\hline SAR & 59 & $22(100 \%)$ & $37(100 \%)$ \\
\hline Atopic dermatitis & 6 & $4(66.6 \%)$ & $2(33.3 \%)$ \\
\hline Asthma & 5 & $3(60 \%)$ & $2(40 \%)$ \\
\hline Food allergy & 3 & $2(66.6 \%)$ & $1(33.3 \%)$ \\
\hline $\begin{array}{l}\text { Total IgE } \\
\text { (UI/mL) }\end{array}$ & $326.8(17.1-2878)$ & $459(83.39-2878)$ & 335.2 \\
\hline Family Hx of atopy & 51 & $20(90.9 \%)$ & $31(83.78 \%)$ \\
\hline
\end{tabular}

Median and corresponding rank values are shown.

SAR: severe allergic rhinitis; y.o.: years old; F: female; M: male

\section{Results}

\section{Demographic Characteristics of Patients}

We finally selected 59 subjects from the outpatient allergy office, 35 females and 24 males; median age 25.8 years, ranging from 9 to 70 years that met the inclusion criteria (Table 1). Majority of the subjects ( $81.35 \%, 48$ out of 59 individuals) had previous clinically confirmed diagnosis of SAR for more than five years, and none of them was formerly treated with allergy immunotherapy (AIT). Participants' median score of individual symptoms on the first outpatients visit was 16 . Despite a diagnosis of SAR, only $66.1 \%$ of the patients (39 out of 59) were properly taking their medication as prescribed by the physician at the time of inclusion in the study. More than
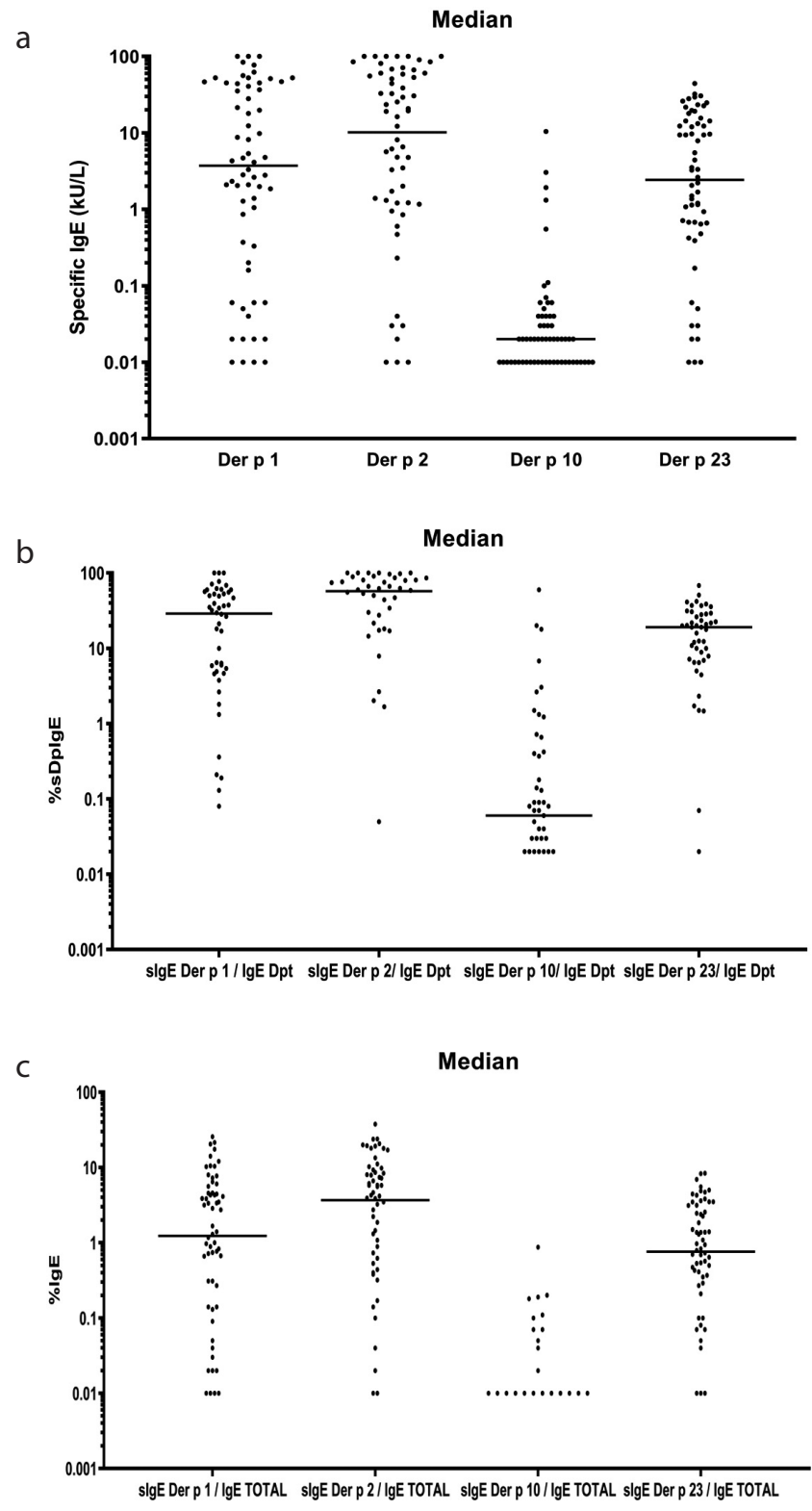

Figure 1. a-c. (a) Serum specific IgE levels of Der $p$ 1, Der $p 2$, Der p 10 and Der p 23, and correlations between the specific IgE levels of Dermatophagoides pteronyssinus (crude extract), (b) total $\mathrm{IgE}$ and (c) single-component Der p 1, Der p 2, Der p 10 and Der p 23 
Table 2. Serological analysis of total $\operatorname{IgE}$ and corresponding specific $\operatorname{IgE}$ responses to the crude extract and molecular allergens of Dermatophagoides pteronyssinus

\begin{tabular}{|c|c|c|c|c|c|c|c|c|c|c|c|c|c|}
\hline $\begin{array}{l}\text { Patient } \\
\text { \# ID }\end{array}$ & $\begin{array}{c}\text { Total } \\
\text { IgE } \\
\text { (UI/mL) }\end{array}$ & $\begin{array}{l}\text { sIgE D. } \\
\text { pter. } \\
(\mathrm{kU} / \mathrm{L})\end{array}$ & $\begin{array}{c}\text { sIgE } \\
\text { Derp 1 } \\
(\mathrm{kUA} / \mathrm{L})\end{array}$ & $\begin{array}{c}\text { sIgE } \\
\text { Der p } 2 \\
(\mathrm{kUA} / \mathrm{L})\end{array}$ & $\begin{array}{c}\text { sIgE } \\
\text { Der p } 10 \\
(\mathrm{kUA} / \mathrm{L})\end{array}$ & $\begin{array}{c}\text { sIgE } \\
\text { Der p } 23 \\
(\mathrm{kUA} / \mathrm{L})\end{array}$ & $\begin{array}{l}\text { Patient } \\
\text { \# ID }\end{array}$ & $\begin{array}{c}\text { Total } \\
\text { IgE } \\
(\mathrm{UI} / \mathrm{mL})\end{array}$ & $\begin{array}{l}\text { sIgE D. } \\
\text { pter. } \\
(\mathrm{kU} / \mathrm{L})\end{array}$ & $\begin{array}{c}\text { sIgE } \\
\text { Der p } 1 \\
(\mathrm{kUA} / \mathrm{L})\end{array}$ & $\begin{array}{c}\text { sIgE } \\
\text { Der p } 2 \\
(\mathrm{kUA} / \mathrm{L})\end{array}$ & $\begin{array}{c}\text { sIgE } \\
\text { Der p } 10 \\
(\mathrm{kUA} / \mathrm{L})\end{array}$ & $\begin{array}{c}\text { sIgE } \\
\text { Der p } 23 \\
(\mathrm{kUA} / \mathrm{L})\end{array}$ \\
\hline 1 & 156.7 & 7.68 & 2.62 & 1.39 & 0.01 & 0.68 & 32 & 1047 & 75.2 & 45.1 & 60.6 & 0.02 & 14.3 \\
\hline 2 & 122.3 & 16.6 & 4.7 & 5.67 & 0 & 1.15 & 34 & 514.6 & $>100$ & 62.2 & 100 & 0.02 & 12.3 \\
\hline 4 & 342.1 & 3.25 & 0.16 & 0.47 & 0.04 & 0.93 & 35 & 229 & 7.18 & 0.33 & 1.22 & 0.01 & 1.14 \\
\hline 5 & 389.7 & 76.6 & 83.8 & 0.04 & 0.02 & 32.2 & 37 & 17.1 & 3.41 & 0.2 & 3.29 & 0 & 0.05 \\
\hline 6 & 331 & 10.9 & 4.31 & 4.8 & 0.01 & 0.71 & 38 & 46.92 & 1 & 0.06 & 0 & 0 & 2.21 \\
\hline 7 & 501.6 & 88.1 & 3.31 & 90.6 & 0.02 & 19.2 & 39 & 871 & 99 & 56.1 & 85.3 & 0.02 & 19.7 \\
\hline 8 & 965.3 & 89 & 44 & 80.8 & 0.06 & 0.02 & 40 & 153.8 & 3.03 & 0.04 & 2.01 & 0.02 & 0 \\
\hline 9 & 1281 & 94.4 & 52.6 & 71.3 & 0.04 & 9.41 & 41 & 322.6 & 5.59 & 0.02 & 1.21 & 0.01 & 2.06 \\
\hline 10 & 256.2 & 66.8 & 19.8 & 51.1 & 0 & 3.33 & 42 & 189.8 & 14.9 & 0.02 & 0 & 0 & 0.01 \\
\hline 11 & 257.7 & 30.8 & 8.17 & 19.1 & 0 & 1.37 & 43 & 263.3 & 32 & 0.06 & 0.85 & 0.03 & 13.2 \\
\hline 12 & 977.2 & $>100$ & 100 & 100 & 0.03 & 30.5 & 44 & 998.9 & 28.4 & 0.06 & 0 & 1.93 & 0.66 \\
\hline 13 & 559.4 & 64 & 4.13 & 100 & 0.05 & 24.8 & 45 & 83.39 & 0.38 & 0.01 & 0.03 & 0.01 & 0.03 \\
\hline 14 & 353 & 61.2 & 21.4 & 32.8 & 0.01 & 12.3 & 46 & 1554 & $>100$ & 52.6 & 66.6 & 3.05 & 21.7 \\
\hline 15 & 2878 & $>100$ & 100 & 100 & 0.06 & 22.6 & 48 & 742.5 & $>100$ & 5.38 & 58.8 & 1.32 & 23.4 \\
\hline 16 & 797.1 & $>100$ & 35.4 & 53.1 & 0.04 & 44.2 & 49 & 83.64 & 7.43 & 2.79 & 3.48 & 0.03 & 0.48 \\
\hline 17 & 744.9 & $>100$ & 77.3 & 100 & 0.02 & 26.1 & 50 & 20.02 & 5.35 & 2.82 & 4.77 & 0.02 & 1.68 \\
\hline 18 & 127.6 & 3.49 & 1.28 & 30.5 & 0 & 0.06 & 51 & 199 & 53 & 40.60 & 12.20 & 0 & 9.71 \\
\hline 19 & 235.4 & 9.9 & 2.1 & 1.72 & 0 & 3.53 & 52 & 211.5 & 21.8 & 2.05 & 1.31 & 0.01 & 0.17 \\
\hline 20 & 295 & 11 & 1.99 & 6.57 & 0.01 & 1.2 & 53 & 571.3 & 14.6 & 4.77 & 6.19 & 0.03 & 7.89 \\
\hline 21 & 135.6 & 13.8 & 9.83 & 0.23 & 0.1 & 9.42 & 54 & 965.3 & $>100$ & 1.39 & 0.01 & 0.04 & 9.38 \\
\hline 22 & 1194 & 57.9 & 1.05 & 1.17 & 10.4 & 29.4 & 55 & 100.4 & 2.93 & 0.02 & 20.80 & 0 & 0 \\
\hline 23 & 2581 & $>100$ & 100 & 100 & 0.07 & 28.1 & 56 & 292.8 & 46.4 & 0.01 & 32.60 & 0.01 & 0.03 \\
\hline 24 & 612 & 87.8 & 28 & 44.2 & 0.04 & 15.6 & 57 & 156.8 & 47.7 & 8.76 & 0.02 & 0.01 & 5.48 \\
\hline 25 & 745.1 & 36.6 & 2.32 & 29.2 & 0.55 & 2.63 & 58 & 181.7 & 3.11 & 46.60 & 68.20 & 0 & 1.5 \\
\hline 26 & 499.6 & 86.6 & 52.6 & 85 & 0.02 & 18 & 59 & 240.5 & 19 & 1.86 & 0.95 & 0.01 & 4.42 \\
\hline 27 & 1707 & $>100$ & 46.8 & 55.5 & 0.02 & 12 & 60 & 42.68 & 3.39 & 36.70 & 25.40 & 0 & 0.42 \\
\hline 28 & 137 & 2.18 & 0.37 & 0.6 & 0 & 0.64 & 61 & 293 & 6.53 & 51.30 & 23.50 & 0.01 & 1.08 \\
\hline 29 & 225 & 26.1 & 17.9 & 19.4 & 0.11 & 9.66 & 62 & 61.55 & 1.99 & 0.86 & 0.00 & 0 & 0 \\
\hline 30 & 667 & 45.3 & 2.1 & 38.8 & 0.02 & 0.68 & & 433.9 & 10.2 & 12.40 & 8.12 & 0.02 & 0 \\
\hline 31 & 596.6 & 26 & 0.02 & 16.3 & 0.02 & 3.25 & \multicolumn{7}{|c|}{ D. pter.: Dermatophagoides pteronyssinus } \\
\hline
\end{tabular}

$86 \%$ (51 out 59 subjects) had a family history of atopy and related comorbidities, five patients were afflicted with mild atopic dermatitis, three had confirmed food allergy (egg, milk and tree nuts, respectively) four had associated intermittent asthma.

Quantification of IgE Serum Responses to the Crude Extract of $D$. Pteronyssinus, HDM Molecular Profile and Total IgE

All 59 patients were $\operatorname{sgE}$ positive $(\geq 0.35 \mathrm{kU} / \mathrm{L})$ against D. pteronyssinus (whole extract), with a mean value of $32.21 \pm 31.06 \mathrm{kU} / \mathrm{L}$, ranging from 0.38 to $>100 \mathrm{kU} / \mathrm{L}$. Globally, up to $93.2 \%$ of the patients ( 55 out of 59 ) were sensitized to major allergens (i.e., either group 1 and/or 2 and/or Der p 23). Regarding individual molecular allergens, Der p 2 was most frequently found in 50 out of 59 patients $(84.74 \%)$, followed by Der p 23 in 48 of 59 (81.35\%) patients, while 46 (77.96\%) patients were positive for Der $\mathrm{p} 1$, and only five out of 59 sera $(8.47 \%)$ exhibited a sIgE to Der p 10. In addition, four patients $(6.77 \%)$ were exclusively sensitized (single-molecular responders) to Der p $2 \mathrm{sIgE}$, with just one patient (1.69\%) showing an individual $s I g E$ response to either Der $\mathrm{p}$ 1 or Der p 23. By contrast, Der p 10 elicited no exclusive $\operatorname{IgE}$ responses in any of the investigated sera samples.

Quantitative median values (ranging in all four individual allergens from 0.01 to $>100 \mathrm{kU} / \mathrm{L}$ ) of sIgE were significantly $(\mathrm{p}=0.01)$ the highest for Der p 2 (17.7) to Der p 1 (4.5), Der p 23 (3.29) and the lowest for Der p $10(<0.35)$. Median ratios of Der p 2 related to total $\operatorname{IgE}$ (Der p 2/total IgE) 


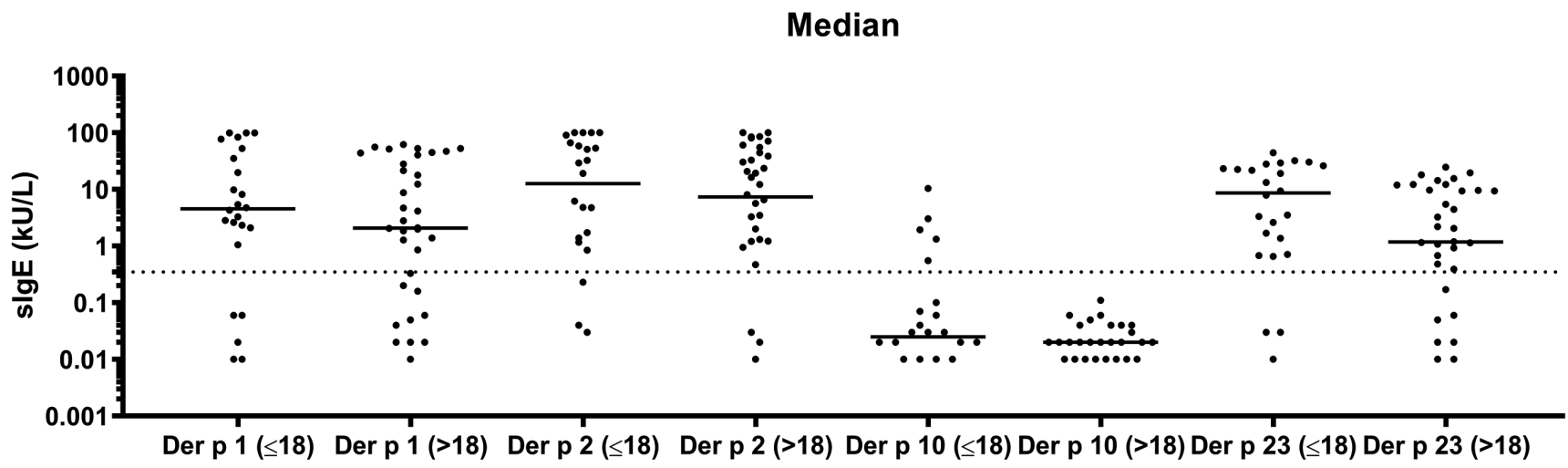

Figure 2. Serum specific IgE levels of Der p 1, Der p 2, Der p 10 and Der p 23 from younger subjects compared to elder patients $(>18$ years of age)

Dermatophagoides pteronyssinus

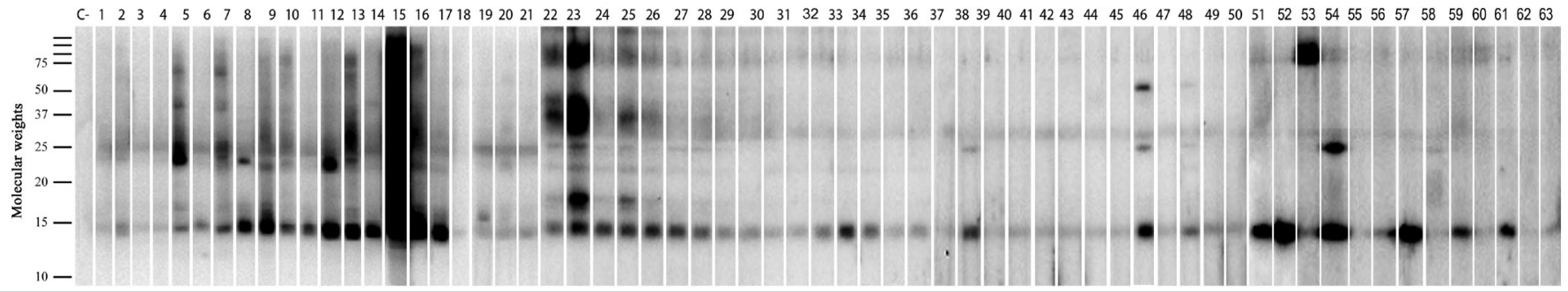

Figure 3. Western blot of selected patients sensitized to Dermatophagoides pteronyssinus with severe allergic persistent rhinitis

and $\operatorname{sg} \mathrm{E}$ to $D$. pteronyssinus whole extract (Der $\mathrm{p} 2 / \mathrm{sIgE} D$. pteronyssinus) were again the highest compared to the rest of single individual allergens (i.e., Der p 1, Der p 23 or Der $\mathrm{p}$ 10), as displayed in Figure 1.

Considering the relation of the sensitization profile of total $\mathrm{IgE}$ and $\operatorname{sgE}$ in relation to age, total $\operatorname{IgE}$ and median value of $326.8 \mathrm{UI} / \mathrm{mL}$ were found in younger patients ( $<18$ years of age), showing a higher median total $\operatorname{IgE}$ than adults, denoting a marked atopic phenotype in the investigated population (Table 2).

Considering the relation of the sensitization profile of total $\operatorname{IgE}$ and $\operatorname{sg} \mathrm{E}$ in relation to age, higher median $\operatorname{IgE}$ and $\operatorname{sg} \mathrm{E}$ values were found in the younger patients $(<18$ years of age) compared to adults, denoting a marked atopic phenotype in the investigated population (Table 2).

Moreover, concurrent sIgE responses to $D$. pteronyssinus (whole extract) were displayed with a significantly $(\mathrm{p}=0.01)$ higher median level of sIgE in younger subjects (D. pteronyssinus: 32.37 to 5.16, ranging 0.01 to $>100 \mathrm{kU} / \mathrm{L}$ in both cases) and a higher median level of sIgE to all major allergens, except for Der $\mathrm{p} 10$ in comparison with their elder counterparts (Figure 2).

\section{SDS PAGE/IgE Western Blot}

Western blot of selected individuals sensitized to $D$. pteronyssinus, including 4 subjects \#3, 33, 36 and 47 with no de- tectable sIgE to the whole extract of $D$. pteronyssinus, showed different repertoires of $\mathrm{IgE}$ response (Figure 3). A notable stain intensity was found at $14-15 \mathrm{kDa}$ for $D$. pteronyssinus in almost all subjects ( $>95 \%)$, followed by protein staining at $24 \mathrm{kDa}$.

\section{Discussion}

The evidence that single allergen components assemble specific additions against a complete mite $\mathrm{IgE}$ response suggests that biological functions of particular mite allergens contribute to their allergenicity (2). In our investigation, a prevailing capacity for $\operatorname{sIgE}$ sensitization to Der p 2 (>80\%), Der p 23 (>80\%) and Der p 1 (>75\%) was confirmed amongst a population with SAR under subtropical climate conditions. These findings are coincident with former reports, showing a higher incidence of $\operatorname{IgE}$ responses to both Der $\mathrm{p} 1$ and Der p 2 than those addressed in Australia (77\%) and Singapore (63\%) (29). The difference can probably be explained by a persistent higher exposure to HDM, with relative humidity as the ultimate feature, to patronize HDM prevalence (30, 31). The tight correlation among $\operatorname{IgE}$ responses to Der $\mathrm{p} 1$, Der $\mathrm{p} 2$ and Der p 23, and D. pteronyssinus, upholds the significance of these allergens in the $\operatorname{IgE}$ recognition profile to $\mathrm{HDM}$ in our region. In addition, the recorded $\mathrm{IgE}$ response against Der p 2 and Der p 23 represented a larger fraction compared to Der p 1, as shown by previous reports in Spain (32). Der p 10 exhibited noticeable titers of $\operatorname{IgE}$ in $8.47 \%$ in the studied sample, showing higher prevalence compared to 
previous works from China $(33,34)$. The elevated prevalence (81.35\%) of Der p $23 \mathrm{sIgE}$-close to Der p 2 (84.74\%)-further confirmed the serodominance of this peritrophin-like protein in SAR, supporting investigations from Europe and Asia $(35,36)$.

The biological proteolytic activity of Der $\mathrm{p} 1$ appears to play a more influential role during the early years of life, while Der p 2 takes the lead in later ages, proposing a higher exposure to Der $\mathrm{p} 1$ rather than Der $\mathrm{p} 2(37,38)$. By contrast, our observations found that although younger individuals showed a higher mean level of sIgE to D. pteronyssinus and to individual allergens compared to elderly patients, the sIgE against Der p 2 was more intense regarding prevalence and individual quantification than Der p 1 and Der p 23 in both infants and adults. Interestingly, despite the high $\mathrm{sIgE}$ response to Der p 23, only one subject (1.69\%) was exclusively sensitized to this allergen-confirming the polyclonal sIgE HDM profile of the current sample-in contrast to previous Austrian data (39) showing $10 \%$ of allergic patients solely responding to Der $\mathrm{p} 23$, excluding otherwise responses to a broad panel of HDM allergens.

Also, previous works from Asia have elegantly confirmed the association among those $\operatorname{sgE}$ profiles enclosing a greater number of HDM allergens, and the intricacy of the evolved allergic clinical endotype $(31,33)$. In addition to these findings, herein we describe multiple and complex IgE repertoires to Der p 1, Der p 2, Der p 23 and Der p 10, within the same underlying disease and degree of severity-i.e., persistent SAR-excluding further atopic conditions such as asthma or eczema.

Concerning HDM minor allergens, the prevalence of $\operatorname{IgE}$ response to the muscular protein tropomyosin was scarce $(<10 \%)$ and limited to younger patients, with no subjects exclusively sensitized to Der p 10 in our observations. As previously reported, those individuals with a sensitization to the HDM group 10 allergens exhibited significantly higher total IgE levels (1,025.2 kU/L) compared to those without a response to Der p 10 (432.7 kU/L), thus enduring Der p 10 as a biomarker to extensive sensitization concerning susceptible allergic population $(40,41)$.

The presented research has a potential bias as four out of 59 (6.77\%) subjects sensitized to the crude extract of D. pteronyssinus were not identified through the composed CRD panel. In this regard, as some HDM allergens may not be sufficiently represented - thus exhibiting lower IgE titers to the HDM raw extract ImmunoCAP (ThermoFisher Scientific, Uppsala, Sweden) the inclusion of more specific tests, adding further recombinant molecular allergens to the complete HDM source or even depicting molecular panels containing the most prevalent allergens, may be suitable to overcome this duty $(42,43)$.

\section{Conclusion}

Our findings showed that the currently proposed HDM molecular panel, including Der p 1, Der p 2 and Der p 23, accurately recognized the large majority ( $>90 \%)$ of $D$. pteronyssinus-allergic subjects afflicted with SAR in an area with a high load of mite allergen exposure. Diverse mite allergens dominate the immediate $\mathrm{IgE}$ response in SAR, with patient variability evolving into individual pleomorphic responses, $\mathrm{CRD}$ arises critical to formulate a further precise molecular diagnosis, and eventually a personalized and tailored HDM immunotherapy.

Ethics Committee Approval: Ethics committee approval was received for this study from the Ethical Committee of the Nuestra Señora de Candelaria University Hospital. (Approval Date: March 28, 2017; Approval Number: P.I.-14/17).

Informed Consent: Informed consent was obtained from the patients who participated in this study.

Peer-review: Externally peer-reviewed.

Author Contributions: Concept - R.G.P., P.P.G.; Design - R.G.P., P.P.G., F.P., M.C.; Supervision - F.P., M.C.; Materials - F.P., M.C.; Data Collection and/or Processing - R.G.P., P.P.G., F.P.; Analysis and/or Interpretation - R.G.P., P.P.G., F.P., M.C.; Literature Search - R.G.P., P.P.G., F.P.; Writing - R.G.P.; Critical Reviews - R.G.P., P.P.G., F.P., M.C.

Conflict of Interest: The authors have no conflicts of interest to declare.

Financial Disclosure: The authors declared that this study has received no financial support.

\section{References}

1. Thomas WR. Geography of house dust mite allergens. Asian Pac J Allergy Immunol 2010; 28: 211-24.

2. Calderón MA, Linneberg A, Kleine-Tebbe J, De Blay F, Rojas DHF, Virchow JC, et al. Respiratory allergy caused by house dust mites: What do we really know? J Allergy Clin Immunol 2015; 136: 38-48. [Crossref]

3. Waldron R, McGowan J, Gordon N, McCarthy C, Mitchell EB, Fitzpatrick DA. Proteome and allergenome of the European house dust mite Dermatophagoides pteronyssinus. PLOS ONE 2019; 14: 1-28. [Crossref]

4. Fernández-Caldas E, Puerta L, Caraballo L. Mites and allergy. Bergmann KC, Ring J, editors. History of allergy, Chem immunol allergy, vol. 100. Basel: Karger; 2014. p. 234-42. [Crossref]

5. Fernández-Caldas E, Fox RW, Bucholtz GA, Trudeau WL, Ledford DK, Lockey RF: House dust mite allergy in Florida. Mite survey in households of mite-sensitive individuals in Tampa, Florida. Allergy Proc 1990; 11: 263-67. [Crossref]

6. Sybilski AJ, Zalewska M, Furmańczyk K, Lipiec A, Krzych-Fałta E, Samoliński B. The prevalence of sensitization to inhalant allergens in children with atopic dermatitis. Allergy Asthma Proc 2015; 36: 81-5. [Crossref]

7. Batard T, Baron-Bodo V, Martelet A, Le Mignon M, Lemoine $\mathrm{P}$, Jain $\mathrm{K}$, et al. Patterns of $\mathrm{IgE}$ sensitization in house dust 
mite-allergic patients: implications for allergen immunotherapy. Allergy 2016; 71: 220-9. [Crossref]

8. Poza Guedes P, Sánchez Machín I, Matheu V, Iraola V, González Pérez R. Role of predatory mites in persistent nonoccupational allergic rhinitis. Can Respir J 2016; 2016: 5783317. [Crossref]

9. WHO/IUIS Allergen Nomenclature Sub-Committee. Allergen Nomenclature. Available from: URL: http://www.allergen. org. Last accessed: February 20, 2020.

10. Weghofer M, Thomas WR, Kronqvist M, Mari A, Purohit A, Pauli $\mathrm{G}$, et al. Variability of $\mathrm{IgE}$ reactivity profiles among European mite allergic patients. Eur J Clin Invest 2008; 38: 959-65. [Crossref]

11. Jacquet A, Robinson C. Proteolytic, lipidergic and polysaccharide molecular recognition shape innate responses to house dust mite allergens. Allergy 2020; 75: 33-53. [Crossref]

12. Ayuso R, Reese G, Leong-Kee S, Plante M, Lehrer SB. Molecular basis of arthropod cross-reactivity: IgE-binding cross-reactive epitopes of shrimp, house dust mite and cockroach tropomyosins. Int Arch Allergy Immunol 2002; 129: 38-48. [Crossref]

13. Becker S, Schlederer T, Kramer MF, Haack M, Vrtala S, Resch $\mathrm{Y}$, et al. Real-life study for the diagnosis of house dust mite allergy - the value of recombinant allergen-based IgE serology. Int Arch Allergy Immunol 2016; 170: 132-7. [Crossref]

14. Resch Y, Michel S, Kabesch M, Lupinek C, Valenta R, Vrtala $\mathrm{S}$. Different $\mathrm{IgE}$ recognition of mite allergen components in asthmatic and nonasthmatic children. J Allergy Clin Immunol 2015; 136: 1083-91. [Crossref]

15. Minami T, Fukutomi Y, Lidholm J, Yasueda H, Saito A, Sekiya $\mathrm{K}$, et al. IgE Abs to Der $\mathrm{p} 1$ and Der $\mathrm{p} 2$ as diagnostic markers of house dust mite allergy as defined by a bronchoprovocation test. Allergol Int 2015; 64: 90-5. [Crossref]

16. Belgü AU, Uçal YO, Ekinci A, Alış MG, Yıldırım Ö, Dizdar D. Assessment of quality of life and coexistent allergic conjunctivitis in patients with allergic rhinitis in Van province. Turk Arch Otorhinolaryngol 2014; 52: 87-92. [Crossref]

17. Bousquet J, Khaltaev N, Cruz AA, Denburg J, Fokkens WJ, Togias A, et al. Allergic rhinitis and its impact on asthma (ARIA) 2008 update (in collaboration with the World Health Organization, GA(2)LEN, and AllerGen). Allergy 2008; 63: 8-160. [Crossref]

18. Custovic A, Sonntag HJ, Buchan IE, Belgrave D, Simpson A, Prosperi MCF. Evolution pathways of $\operatorname{IgE}$ responses to grass and mite allergens throughout childhood. J Allergy Clin Immunol 2015; 136: 1645-52. [Crossref]

19. Gaffin JM, Phipatanakul W. The role of indoor allergens in the development of asthma. Curr Opin Allergy Clin Immunol 2009; 9: 128-35. [Crossref]

20. Valenta R, Lidholm J, Niederberger V, Hayek B, Kraft D, Grönlund H. The recombinant allergen-based concept of component-resolved diagnostics and immunotherapy (CRD and CRIT). Clin Exp Aller $\neg$ gy 1999; 29: 896-904. [Crossref]

21. Ebo DG, Hagendorens MM, De Knop KJ, Verweij MM, Bridts CH, De Clerck LS, et al. Component-resolved diagnosis from latex allergy by microarray. Clin Exp Allergy 2010; 40: 348-58. [Crossref]

22. Thomas WR. Hierarchy and molecular properties of house dust mite allergens. Allergol Int 2015; 64: 304-11. [Crossref]

23. Mueller GA, Randall TA, Glesner J, Pedersen LC, Perera L, Edwards LL, et al. Serological, genomic, and structural analyses of the major mite allergen Der p 23. Clin Exp Allergy 2016; 46: 365-76. [Crossref]

24. Iraola Calvo V, Fernández-Caldas E. Mapa acarológico de España. Barcelona: Laboratorios Leti; 2009. Available from: URL: https://alergia.leti.com/es/mapa-acarologico_13421
25. González-Pérez R, Pineda F, Poza-Guedes P, Castillo M, Matheu V, Sánchez-Machín I. Molecular allergen profiling of dual mite sensitization in severe allergic rhinitis. J Investig A1lergol Clin Immunol 2019 Sep 18:0. doi: 10.18176/jiaci.0439. [Epub ahead of print]. [Crossref]

26. Pfaar O, Demoly P, Gerth van Wijk R, Bonini S, Bousquet J, Canonica GW, et al. Recommendations for the standardization of clinical outcomes used in allergen immunotherapy trials for allergic rhinoconjunctivitis: an EAACI position paper. Allergy 2014; 69: 854-67. [Crossref]

27. Heinzerling L, Mari A, Bergmann KC, Bresciani M, Burbach $\mathrm{G}$, Darsow U, et al. The skin prick test - European standards. Clin Transl Allergy 2013; 3: 3. [Crossref]

28. Laemmli, UK. Cleavage of structural proteins during the assembly of the head of bacteriophage T4. Nature 1970; 227: 680-5. [Crossref]

29. Bronnert M, Mancini J, Birnbaum J, Agabriel C, Liabeuf V, Porri F, et al. Component- resolved diagnosis with commercially available D. pteronyssinus Der p 1, Der p 2 and Der p 10: relevant markers for house dust mite allergy. Clin Exp Allergy 2012; 42: 1406-15. [Crossref]

30. Hales BJ, Martin AC, Pearce LJ, Laing IA, Hayden CM, Goldblatt $\mathrm{J}$, et al. $\mathrm{IgE}$ and $\mathrm{IgG}$ anti-house dust mite specificities in allergic disease. J Allergy Clin Immunol 2006; 118: 361-7. [Crossref]

31. Kidon MI, Chiang WC, Liew WK, Ong TC, Tiong YS, Wong $\mathrm{KN}$, et al. Mite component-specific IgE repertoire and phenotypes of allergic disease in childhood: the tropical perspective. Ped Allergy Immunol 2011; 22: 202-10. [Crossref]

32. Vidal C, Lojo S, Juangorena M, Gonzalez-Quintela A. Association between asthma and sensitization to allergens of dermatophagoides pteronyssinus. J Investig Allergol Clin Immunol 2016; 26: 304-9. [Crossref]

33. Chen ZG, Li YT, Wang WH, Tan KS, Zheng R, Yang LF, et al. Distribution and determinants of dermatophagoides mites sensitization of allergic rhinitis and allergic asthma in China. Int Arch Allergy Immunol 2019; 180: 17-27. [Crossref]

34. Wang HY, Gao ZS, Zhou X, Dai Y, Yao W, Zhang XF et al. Evaluation of the role of $\operatorname{IgE}$ responses to Der $\mathrm{p} 1$ and Der $\mathrm{p} 2$ in Chinese house dust mite-allergic patients. Int Arch Allergy Immunol 2015; 167: 203-10. [Crossref]

35. Banerjee S, Weber M, Blatt K, Swoboda I, Focke-Tejkl M, Valent $\mathrm{P}$, et al. Conversion of Der p 23, a new major house dust mite allergen, into a hypoallergenic vaccine. J Immunol 2014; 192: 4867-75. [Crossref]

36. Soh WT, Le Mignon M, Suratannon N, Satitsuksanoa P, Chatchatee $\mathrm{P}$, Wongpiyaboron J, et al. The house dust mite major allergen Der $\mathrm{p} 23$ displays $\mathrm{O}$-glycan-independent IgE reactivities but no chitin-binding activity. Int Arch Allergy Immunol 2015; 168: 150-60. [Crossref]

37. Herman J, Thelen N, Smargiasso N, Mailleux AC, Luxen A, Cloes $M$, et al. Der $p 1$ is the primary activator of Der $p 3$, Der p 6 and Der p 9 the proteolytic allergens produced by the house dust mite Dermatophagoides pteronyssinus. Biochim Biophys Acta 2014; 1840: 1117-24. [Crossref]

38. Chen HL, Su HJJ, Lin LL. Distribution variations of multi allergens at asthmatic children's homes. Sci Total Environ 2002; 289: 249-54. [Crossref]

39. Weghofer M, Grote M, Resch Y, Casset A, Kneidinger M, Kopec J, et al. Identification of Der p 23, a peritrophin-like protein, as a new major Dermatophagoides pteronyssinus allergen 
associated with the peritrophic matrix of mite fecal pellets. J Immunol 2013; 190: 3059-67. [Crossref]

40. Resch Y, Weghofer M, Seiberler S, Horak F, Scheiblhofer S, Linhart B, et al. Molecular characterization of Der p 10: a diagnostic marker for broad sensitization in house dust mite allergy. Clin Exp Allergy 2011; 41: 1468-77. [Crossref]

41. Posa D, Perna S, Resch Y, Lupinek C, Panetta V, Hofmaier S. et al. Evolution and predictive value of $\mathrm{IgE}$ responses toward a comprehensive panel of house dust mite allergens during the first 2 decades of life. J Allergy Clin Immunol 2017; 139: 541-9. [Crossref]
42. Huang HJ, Resch-Marat Y, Rodriguez-Dominguez A, Chen KW, Kiss R, Petra Zieglmayer P, et al. Underestimation of house dust mite-specific IgE with extract-based ImmunoCAPs compared with molecular ImmunoCAPs. J Allergy Clin Immunol 2018; 142: 1656-9. [Crossref]

43. Lupinek C, Wollmann E, Baar A, Banerjee S, Breiteneder H, Broecker BM, et al. Advances in allergen-microarray technology for diagnosis and monitoring of allergy: the MeDALL allergen-chip. Methods 2014; 66: 106-19. [Crossref] 